\title{
Preparation and Application of Polyurethane Coating Material Based on Epoxycyclohexane-Epoxychloropropane Protective for Paper
}

\author{
Juan Liu ${ }^{1}$, Shan-Shan Jin ${ }^{2}$, Ying-Ping $\mathrm{Qi}^{3}$, Yong-Feng Shen ${ }^{3}$ and Hua $\mathrm{Li}^{2, *}$ \\ 1 Department of Pharmacy, Kangda College of Nanjing Medical University, Lianyungang 222000, China; \\ liujuan281@njmu.edu.cn \\ 2 School of Chemical Engineering, Zhengzhou University, Zhengzhou 450001, China; 15737953500@163.com \\ 3 Department of Preservation, Zhengzhou Museum, Zhengzhou 450000, China; k365667769@163.com (Y.-P.Q.); \\ 13215856433@163.com (Y.-F.S.) \\ * Correspondence: lihua@zzu.edu.cn
}

Citation: Liu, J.; Jin, S.-S.; Qi, Y.-P.; Shen, Y.-F.; Li, H. Preparation and Application of Polyurethane Coating Material Based on EpoxycyclohexaneEpoxychloropropane Protective for Paper. Coatings 2021, 11, 1005. https://doi.org/10.3390/coatings 11081005

Received: 23 July 2021

Accepted: 18 August 2021

Published: 23 August 2021

Publisher's Note: MDPI stays neutral with regard to jurisdictional claims in published maps and institutional affiliations.

Copyright: (c) 2021 by the authors. Licensee MDPI, Basel, Switzerland. This article is an open access article distributed under the terms and conditions of the Creative Commons Attribution (CC BY) license (https:// creativecommons.org/licenses/by/ $4.0 /)$.

\begin{abstract}
Paper historic relics are of great value to research and preserve. However, with the change of environment, paper cultural relics are constantly aging and damaged. Therefore, the reinforcement and conservation of the paper is an important topic in the field of cultural relics protection; thus, it is a crucial and arduous task to discover high-performance protective materials. The coating reinforcement method is a kind of commonsense method to strengthen the paper. Additionally, it is key to select appropriate reinforcing resins. Polyurethane has influence on the improvement of paper strength, stability, and appearance. The epoxycyclohexane-epoxychloropropane polyether polyol was prepared with epoxycyclohexane and epoxychloropropane as materials, glycerol as the initiator, boron trifluoride diethyl etherate as the catalyst, and dichloromethane as the solvent. Infrared (IR) spectroscopy as well as proton nuclear magnetic resonance $\left({ }^{1} \mathrm{HNMR}\right)$ spectroscopy were adopted to characterize the structure of the synthetic copolyether. Then, polyurethane based on epoxycyclohexane-epoxychloropropane was prepared by the synthetic copolyether reacting with hexamethylene diisocyanate (HDI) trimer. The effect of the mass concentration of polyurethane on the tensile strength, elongation, folding endurance, and the tearing strength of paper samples were tested. When $10 \%$ polyurethane solution was applied to paper, not only were the mechanical properties greatly improved, but the gloss and brightness also changed slightly, which conformed to the principle of "repair as old". The above results indicate that the synthetic polyurethane combines the advantages of epoxycyclohexane-poxychloropropane polyether polyol along with polyurethane, presenting excellent properties in paper reinforcement or conservation.
\end{abstract}

Keywords: polyether polyol; polyurethane; paper conservation

\section{Introduction}

Paper historic relics, precious materials recording human history, culture, science and technology, have important historical, cultural, artistic, and reference value. It has been identified that there are nearly 2.5 million $\mathrm{km}$ of paper works collected in libraries or archives around the world currently [1-6]. However, paper historic relics are organic artifacts that are highly susceptible to aging and deterioration. They have to withstand not only the vicissitudes of history, but also erosion from environmental pollution, oxygen, light, temperature, biology, and water, which has led to the conundrum of paper conservation throughout the world [7]. Therefore, the reinforcement and conservation of paper is an important topic in the field of cultural relics protection; thus, it is a crucial and arduous task to discover high-performance protective materials. Coating reinforcement method is a kind of commonsense method to strengthen the paper [8]. Additionally, it is key to select appropriate reinforcing resins. 
Paper is processed to form natural or synthetic resin coatings in the coating reinforcement method. Moreover, polyurethane coatings are adopted for their corrosion, water and abrasion resistance; paper strength; and low processing temperature. Nevertheless, polyurethane has instabilities and turns yellow easily $[9,10]$. Transparent polyurethane is prepared based on polyether polyol. Polyether polyols are made from chains of polymerized molecules containing an ether link ( $\mathrm{R}-\mathrm{O}-\mathrm{R})$ and a hydroxyl-terminated. In the presence of an appropriate catalyst, polyether polyols are obtained by ring-opening polymerization. The ring-opening polymerization occurs through a small molecule compound containing an epoxy structure, with a compound possessing a reactive hydrogen atom $\left(-\mathrm{OH},-\mathrm{NH}_{2}\right.$, etc. $)$ as the starting agent [11]. The prepared transparent polyurethane combines the excellent properties of polyether polyol and polyurethane, and presents a high degree of transparency [12]. The opacity of conventional polyurethane materials is due to microphase dispersion and surface light dispersion. Furthermore, the dispersion is caused by microscopic incompatibility between the hard and soft segments. The factors influencing the polyurethane opacity are synthesis routes, types of isocyanate, components of chain extender, components of flexible segment, molecular weight, components of flexible segment, and thermal history, especially the crystallization of the segments [13-16]. It has an insignificant effect on the transparency when the hard and soft segments are crystallized. By ring-opening polymerization of epoxycyclohexane, the polyether polyol molecule obtained not only has the solidity of the six-membered ring, but also has the high activity characteristics of the ternary epoxy group. The solidity of the six-membered ring improves the anti-reciprocating folding ability of paper at a certain tension. Coupled with its large steric hindrance, the synthetic polyether molecular chain is disordered, transparent, and not easy to crystallize. Meanwhile, for the linear structure of epoxychloropropane, the hardness of copolyether decreases and the fluidity increases [17-19]. At the same time, the introduction of a chlorine atom in epoxychloropropane will give polyurethane some new properties, such as flame retardancy and good adhesive properties [20]. The synthetic, transparent polyurethane penetrated well into the paper fibers, forming a three-dimensional crosslinking system among the fibers [21].

At present, the polyurethane based on epoxycyclohexane-epoxychloropropane was prepared by the synthetic polyether polyol and HDI trimer, then applied to paper conservation. In this case, polyurethane has an influence on the improvement of paper mechanical properties [22].

\section{Materials and Methods}

\subsection{Materials}

Epoxycyclohexane (molecular weight: 98.14, relativedensity: 0.97, and CAS number: 286-20-4), industrial grade, was purchased from Shenma Group (Pingdingshan, China). HDI trimer (molecular weight: 627.61, relative density: 1.20, and CAS number: 3779-63-3), industrial grade, was from Bayer (Leverkusen, Germany). Epoxychloropropane (molecular weight: 92.52, relative density: 1.18, and CAS number: 106-89-8), dichloromethane (molecular weight: 84.94, relative density: 1.33, and CAS number: 75-09-2), glycerol (molecular weight: 92.09, relative density: 1.26, and CAS number: 56-81-5), tetramethylsilane (molecular weight: 88.22 , relative density: 0.648 , and CAS number: 75-76-3) and ethyl acetate (molecular weight: 88.10, relative density: 0.90, and CAS number: 141-78-6) were of analytical grade, obtained from Tianjin Komeo Chemical Reagent Co., Ltd. (Tianjin, China). Anhydrous ethanol (molecular weight: 0.79, relative density: 46.07, and CAS number: 64-17-5), dibutyltin dilaurate (molecular weight: 631.57, relative density: 1.05 , and CAS number: 77-58-7), N,N-Dimethylformamide (molecular weight: 73.79, relative density: 0.945, and CAS number: 68-12-2) and sodium hydroxide (molecular weight: 40.01, relative density: 2.12, and CAS number: 1310-73-2) were of analytical grade, obtained from Tianjin Chemical Reagent Plant 3 (Tianjin, China). Boron trifluoride diethyl etherate (molecular weight: 141.94, relative density: 1.15, and CAS number: 109-63-7) was of analytical 
grade and purchased from Shanghai Aladdin Biochemical Technology Co., Ltd. (Shanghai, China). Xuan paper was obtained from the Xuan Paper Company (Xuancheng, China).

\subsection{Preparation of Epoxycyclohexane-Epoxychloropropane Polyether Polyol}

In the presence of the catalyst boron trifluoride diethyl etherate, the copolyether was obtained by ring-opening polymerization through the epoxy structure, with epoxycyclohexane and epoxychloropropane as the starting materials, glycerol as the initiator, and dichloromethane as the solvent $[6,23]$. A total of $0.69 \mathrm{~g}$ glycerol (the molar ratio between glycerol and the starting materials is $0.03: 1), 1.22 \mathrm{~g}$ boron trifluoride diethyl etherate (the molar ratio between the catalyst and the starting materials is $0.035: 1$ ), and $20 \mathrm{~mL}$ dichloromethane were added into a $250 \mathrm{~mL}$ three-neck flask, then epoxycyclohexane and epoxychloropropane (as the starting materials in the molar ratio of 3:4) were added slowly in drops. Boron trifluoride diethyl etherate reacted with glycerol in dichloromethane solvent to form a reactive group. With the catalysis of the reactive group, the ring-opening polymerization of epoxycyclohexane and epoxychloropropane proceeded at $5{ }^{\circ} \mathrm{C}$ for $3-6 \mathrm{~h}$, then the copolyether was obtained [20,23]. After the reaction, the $\mathrm{pH}$ of the product was adjusted to be weakly alkaline, and the ultimate copolyether was obtained by distilled water washing and vacuum distillation [6], which was then transparent and colorless.

\subsection{Preparation of Polyurethane Based on Epoxycyclohexane-Epoxychloropropane Polyether Polyol}

The obtained $5 \mathrm{~g}$ of epoxycyclohexane-epoxychloropropane polyether polyol was mixed with $40 \mathrm{~g}$ of HDI trimer, followed by $30 \mathrm{~g}$ of ethyl acetate added later; dibutyltin dilaurate was used as the catalyst. The reaction proceeded at $70^{\circ} \mathrm{C}$. The content of the isocyanate group (-NCO) was measured at hourly interval, and the reaction was terminated until the content of $-\mathrm{NCO}$ was $15 \%$.

\subsection{Paper Coating}

Firstly, Xuan paper, being analogous to the paper applied in historic relics [24], was cropped into the standard size of $210 \mathrm{~mm} \times 297 \mathrm{~mm}$. Secondly, both sides of the paper in the experimental and control group were dipped in different concentrations of polyurethane liquids(ethyl acetate as the solvent) and ethyl acetate separately for 2-5 min, then dried at room temperature. The coating procedures are shown in Figure 1.

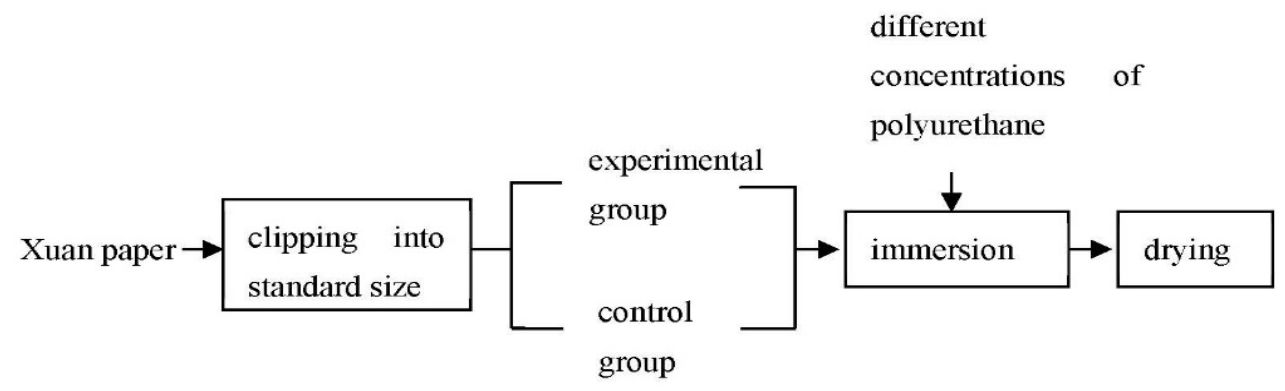

Figure 1. Coating procedures.

\subsection{Analysis and Testing Methods}

By reference to Chinese standard GB/T12914-2008 (ISO 12914-2:1994, MOD) [25], the determination of the tensile strength of the paper was proceeded by a PN-TT300 (Hangzhou Pin Heng Technology Co. Ltd., Hangzhou, China) at $20 \mathrm{~mm} / \mathrm{min}$, and the paper was cropped to a $24.0 \mathrm{~cm} \times 1.5 \mathrm{~cm}$ size. By reference to the Chinese standard GB/T4572008 (ISO5626:1993, MOD) [26], determination of the folding endurance of the paper was proceeded by a double-fold instrument PN-NZ135 (Hangzhou Pin Heng Technology Co. Ltd., Hangzhou, China) at a force of $4.9 \mathrm{~N}$, and the paper samples were cropped to a $15.0 \mathrm{~cm} \times 1.5 \mathrm{~cm}$ size. By reference to the Chinese standard GB/T455-2002 (equiv. ISO 1974:1990) [27], determination of the tearing strength of the paper was proceeded by the 
PN-TT1000 (Hangzhou Pin Heng Technology Co. Ltd., Hangzhou, China); the paper was also cropped to a $6.5 \mathrm{~cm} \times 5.0 \mathrm{~cm}$ size. By reference to the Chinese standard GB/T 89412013 (ISO 8254-1-2009, MOD) [28], determination of the gloss of the paper was proceeded by a glossmeter of PN-GM (Hangzhou Pin Heng Technology Co. Ltd., Hangzhou, China) in modes of G20, G60, and G75. By reference to the Chinese standard GB/T 7974-2013 (ISO 2470:1999, MOD) [29], determination of the brightness of the paper was proceeded by a PN-48B brightness tester (Hangzhou Pin Heng Technology Co. Ltd., Hangzhou, China). Modes of blue and green light diffuse reflectance spectra (R457 and Ry) were chosen [6,23]. IR was tested by Fourier transform infrared spectrometer TENSOR 27 (Bruker Optics, Karlsruhe, Germany) with a resolution of $4 \mathrm{~cm}^{-1}$ and a spectral range of $350 \sim 4000 \mathrm{~cm}^{-1}$. ${ }^{1} \mathrm{HNMR}$ was tested by a $400 \mathrm{MHz}$ WB solid-state nuclear magnetic resonance spectrometer (Bruker Optics, Karlsruhe, Germany). Gel permeation chromatography was tested by gel permeation chromatography IR300 (Thermo Nicolet Corporation, Madison, WI, USA) with a flow velocity of $1.0 \mathrm{~mL} / \mathrm{min}$ and a column temperature of $30^{\circ} \mathrm{C}$. The scanning electron microscope was tested by scanning electron microscope NovaNano SEM450 (FEI, Hillsboro, OR, USA).

\section{Results and Discussion}

\subsection{The Reaction Mechanism of Epoxycyclohexane-Epoxychloropropane Polyether Polyol}

In the presence of the catalyst boron trifluoride diethyl etherate, the copolyether was obtained by cationic ring-opening polymerization through the epoxy structure, with epoxycyclohexane and epoxychloropropane as the starting materials, glycerol as the initiator, and dichloromethane as the solvent $[6,23,30]$. Glycerol reacts with boron trifluoride diethyl etherate, then the resulting intermediate product and epoxycyclohexane react to form an oxonium ion with a positive charge in the active center. This undergoes a nucleophilic reaction with the active oxygen-containing groups of epoxycyclohexane and epoxychloropropane. The process of ring-opening polymerization is divided into chain initiation stage, chain growth stage and chain termination stage [21]. The reaction mechanism can be seen in Scheme 1.

The first step:

$$
\mathrm{BF}_{3} \cdot \mathrm{OEt}_{2}+\mathrm{HOCH}_{2} \mathrm{CHOHCH}_{2} \mathrm{OH} \rightleftharpoons\left[\mathrm{BF}_{3} \mathrm{OCH}_{2} \mathrm{CHOHCH}_{2} \mathrm{OH}\right]{ }_{\mathrm{H}}^{\ominus}+\mathrm{OEt}_{2}
$$

The second step:
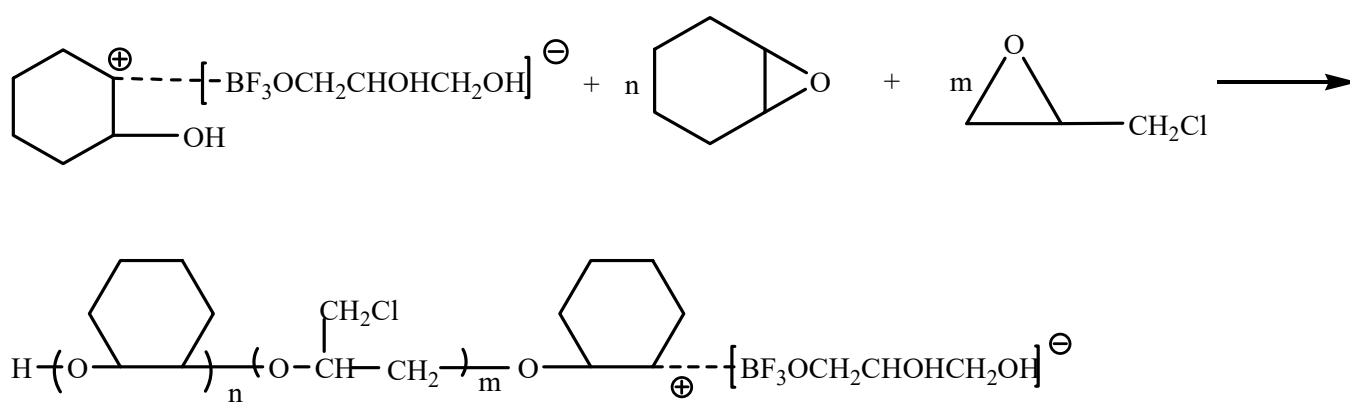

Scheme 1. Cont. 
The third step:

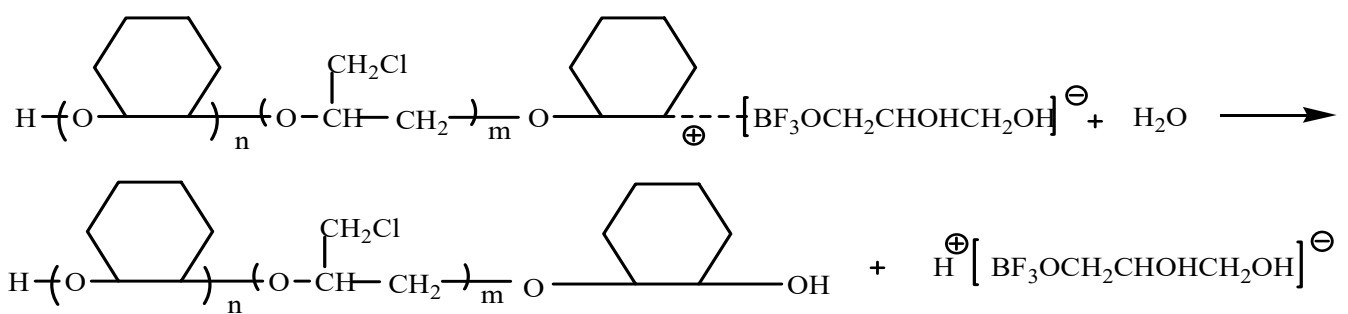

The total reaction is as follows:

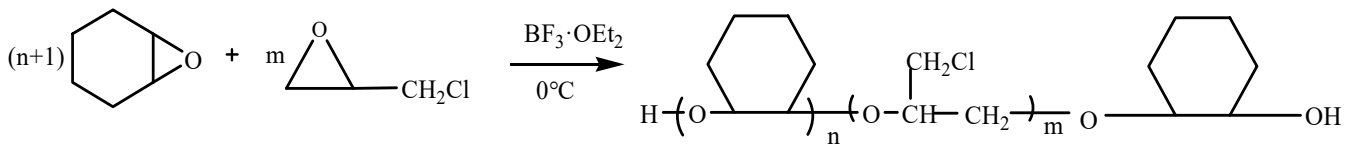

Scheme 1. Reaction mechanism.

The synthesis process of epoxycyclohexane-epoxychloropropane polyether polyol can be seen in Figure 2.

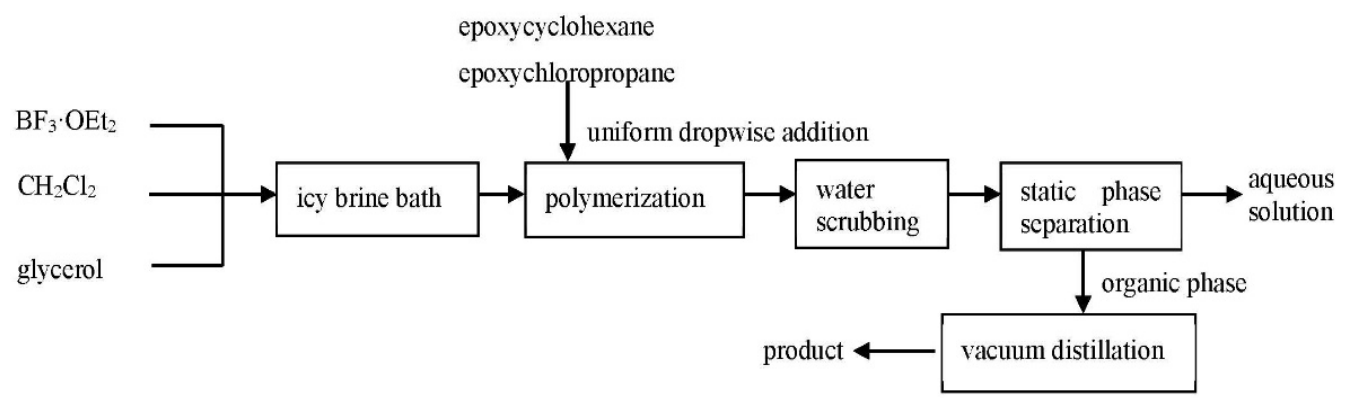

Figure 2. Synthesis process of copolyether.

The IR spectrum of the copolyether is shown in Figure 3. According to the IR spectrum, the characteristic absorption peak of hydroxyl group is at $3347 \mathrm{~cm}^{-1}$. The strong absorption peaks at $2930 \mathrm{~cm}^{-1}$ and $2857 \mathrm{~cm}^{-1}$ are methylene and methine groups, respectively. The absorption peak of the aliphatic ether bond is at $1083 \mathrm{~cm}^{-1}$, and the peak was chosen as an iconic functional group of copolyether. The absorption peak of carbon-chlorine bond is at $780 \mathrm{~cm}^{-1}$.

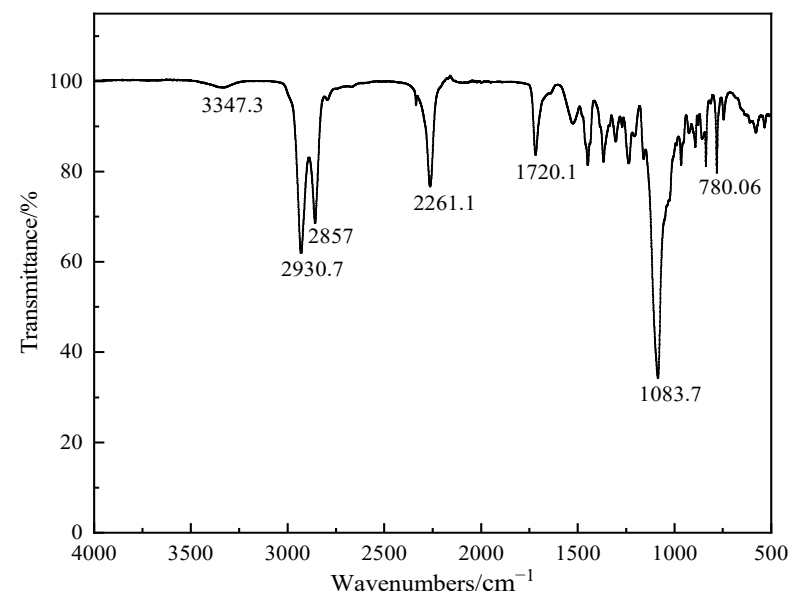

Figure 3. IR spectroscopy of the synthetic copolyether(dissolving with dichloromethane, then coating a thin film, resolution of $4 \mathrm{~cm}^{-1}$, spectral range of $350 \sim 4000 \mathrm{~cm}^{-1}$ ).

${ }^{1} \mathrm{HNMR}$ analysis of the copolyether is shown in Table 1. 
Table 1. ${ }^{1} \mathrm{HNMR}$ analysis of the copolyether.

\begin{tabular}{cc}
\hline Characteristic Functional Groups & Chemical Shift $\boldsymbol{\delta}, \mathbf{p p m}$ \\
\hline$a$ & 3.9 \\
$b$ & 3.6 \\
$c$ & 3.7 \\
$d$ & 3.3 \\
$e$ & 2.0 \\
$f$ & 1.6 \\
\hline
\end{tabular}

The representative $\mathrm{H}$ of $a, b, c, d, e$ and $f$ are showed in Figure 4 , and the ${ }^{1} \mathrm{HNMR}$ spectroscopy of the copolyether is shown in Figure 5.

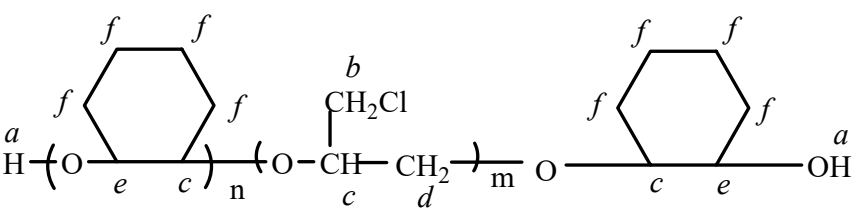

Figure 4. Structure analysis.

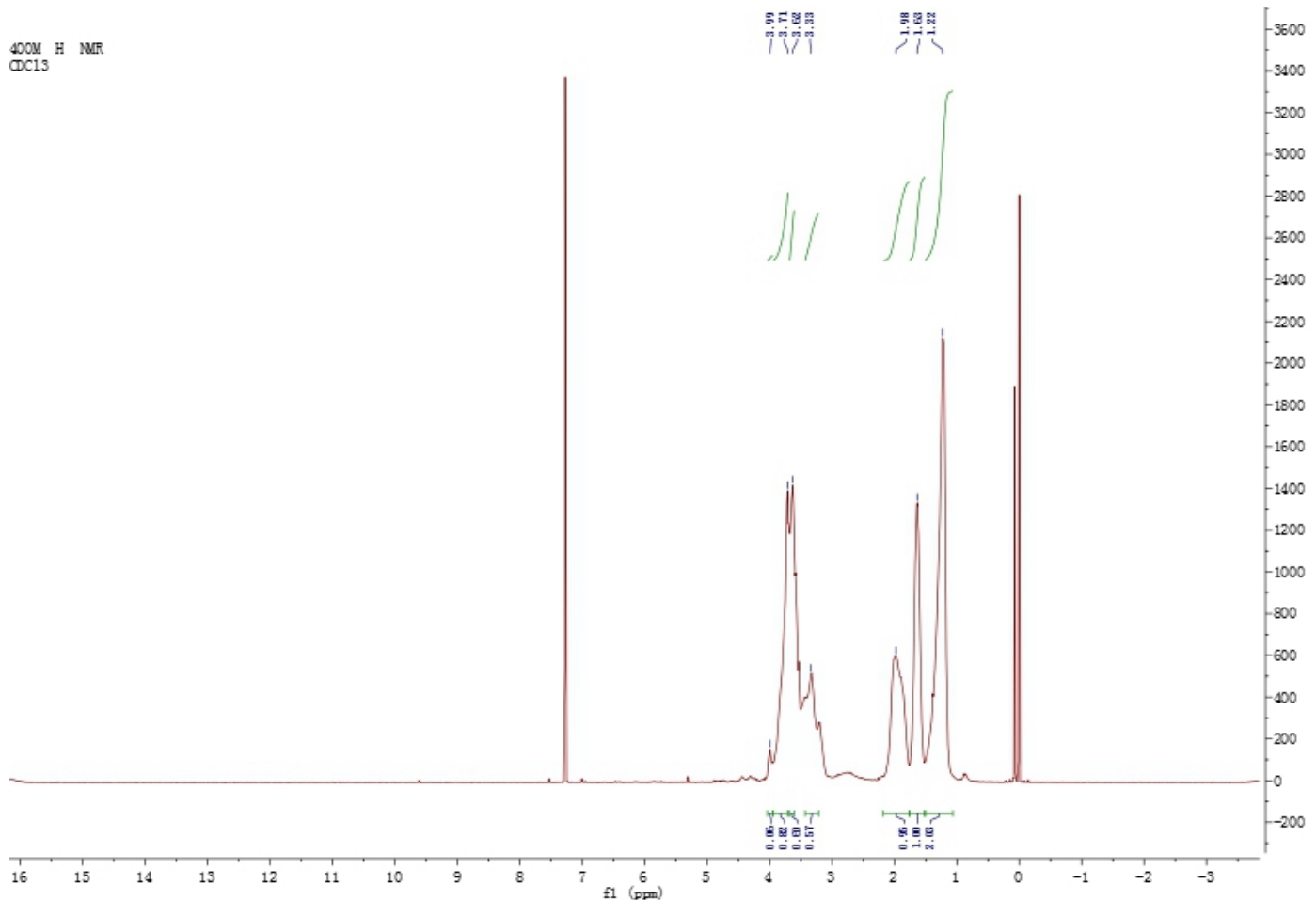

Figure 5. ${ }^{1} \mathrm{HNMR}$ of the synthetic copolyether (dissolving in $\mathrm{CDCl}_{3}$, tetramethylsilane as an internal standard, $400 \mathrm{MHz}$ of resonance frequency).

As illustrated in Figure 5, the proton peaks of methylene in the residual monomers of epoxycyclohexane are between $\delta 1.0$ and 2.0. In addition, methine in the residual monomers of epoxycyclohexane, and all $\mathrm{H}$ atoms in the residual monomers of epoxychloropropane are between $\delta 3.0$ and 4.0. Combined with the IR spectrum, it is suggested that the copolyether was obtained by ring-opening polymerization through the epoxy structure, with epoxycyclohexane and epoxychloropropane as the starting materials.

The obtained copolyether was dissolved with $N, N$-Dimethylformamide, treated and analyzed by gel permeation chromatography; the results were as follows: $\overline{M w}=2547.29$, $\overline{M n}=2473, \mathrm{D}=\overline{M w} / \overline{M n}=1.03 . \overline{M w}$ : the average molecular weight; $\overline{M n}$ : number-average 
molar weight; D: molecular weight dispersion. The gel permeation chromatogram of the synthetic copolyether is shown in Figure 6.

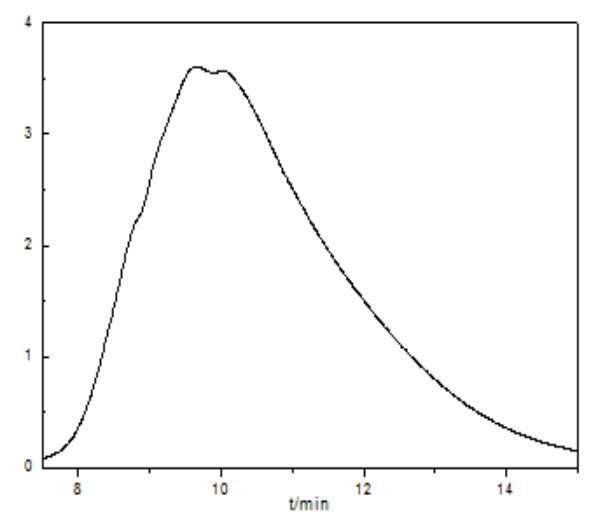

Figure 6. Gel permeation chromatogram of the synthetic copolyether (dissolving with $N, N$ Dimethylformamide, flow velocity of $1.0 \mathrm{~mL} / \mathrm{min}$, column temperature of $30^{\circ} \mathrm{C}$ ).

\subsection{Properties of Polyurethane Based on Epoxycyclohexane-Epoxychloropropane Polyether Polyol}

The polyurethane material was synthesized using epoxycyclohexane-epoxychloropropane polyether polyol and HDI trimer. The reaction mechanism is shown in Scheme 2. With dibutyltin dilaurate as the catalyst, the isocyanate groups of the HDI trimer are highly reactive with hydroxyl groups of epoxycyclohexane-epoxychloropropane polyether polyol.

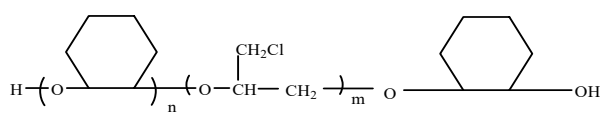

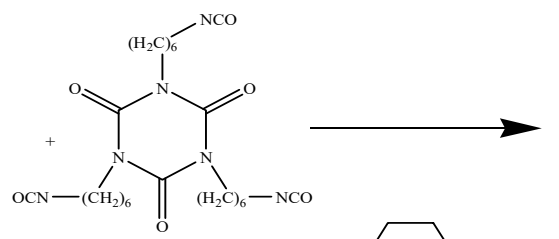

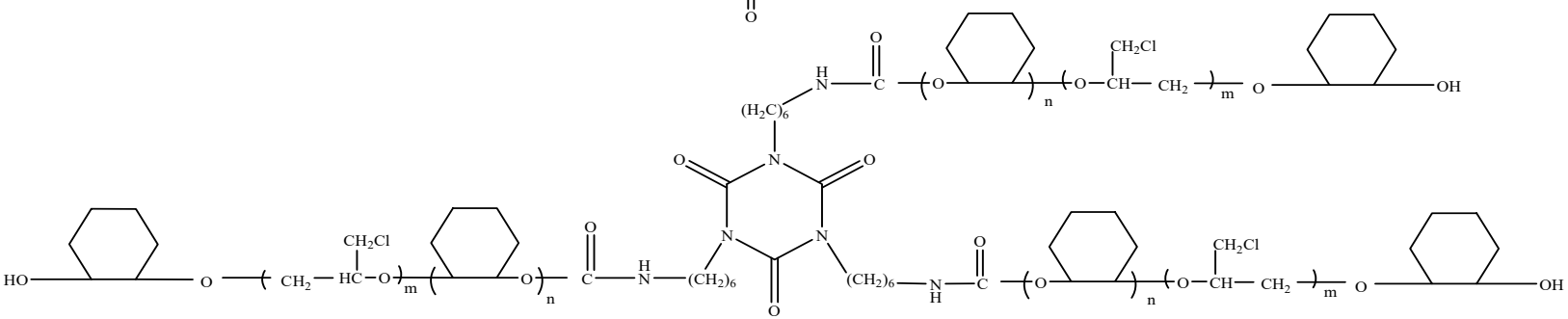

Scheme 2. The reaction mechanism of polyurethane based on epoxycyclohexane-epoxychloropropane polyether polyol.

${ }^{1}$ HNMR analysis of the synthetic polyurethane is shown in Table 2.

Table 2. ${ }^{1} \mathrm{HNMR}$ analysis of the synthetic polyurethane.

\begin{tabular}{cc}
\hline Characteristic Functional Groups & Chemical Shift $\boldsymbol{\delta}, \mathbf{p p m}$ \\
\hline$a$ & 3.9 \\
$b$ & 3.6 \\
$c$ & 3.7 \\
$d$ & 3.3 \\
$e$ & 2.0 \\
$f$ & 1.6 \\
$g$ & $5-9$ \\
\hline
\end{tabular}

The representative $\mathrm{H}$ of $a, b, c, d, e, f$ and $g$ are showed in Figure 7 , and the ${ }^{1} \mathrm{HNMR}$ spectroscopy of the epoxycyclohexane-epoxychloropropane-based polyurethane is shown in Figure 8. 


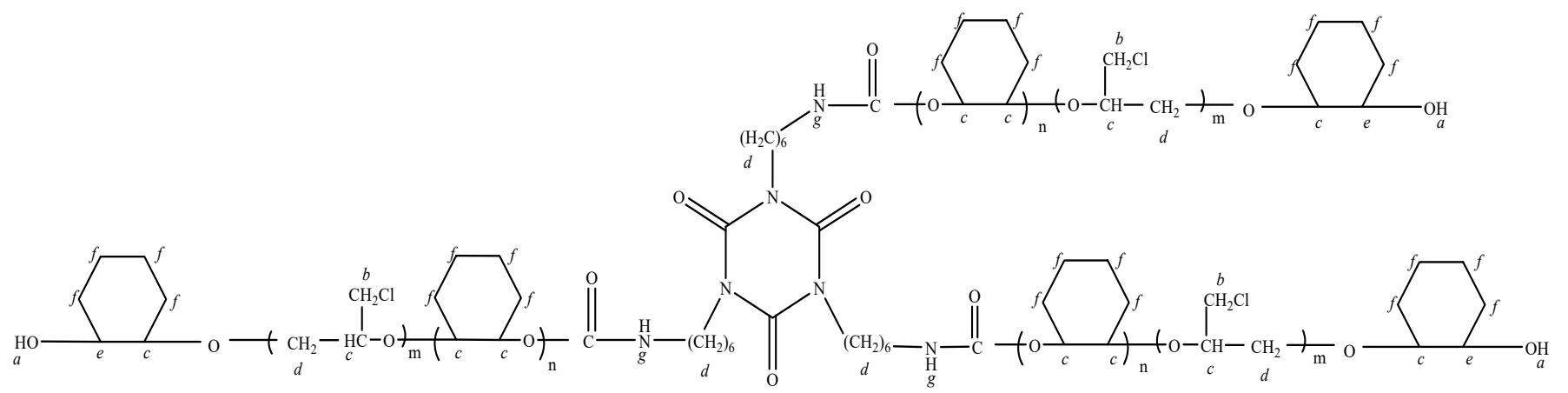

Figure 7. Structure analysis.

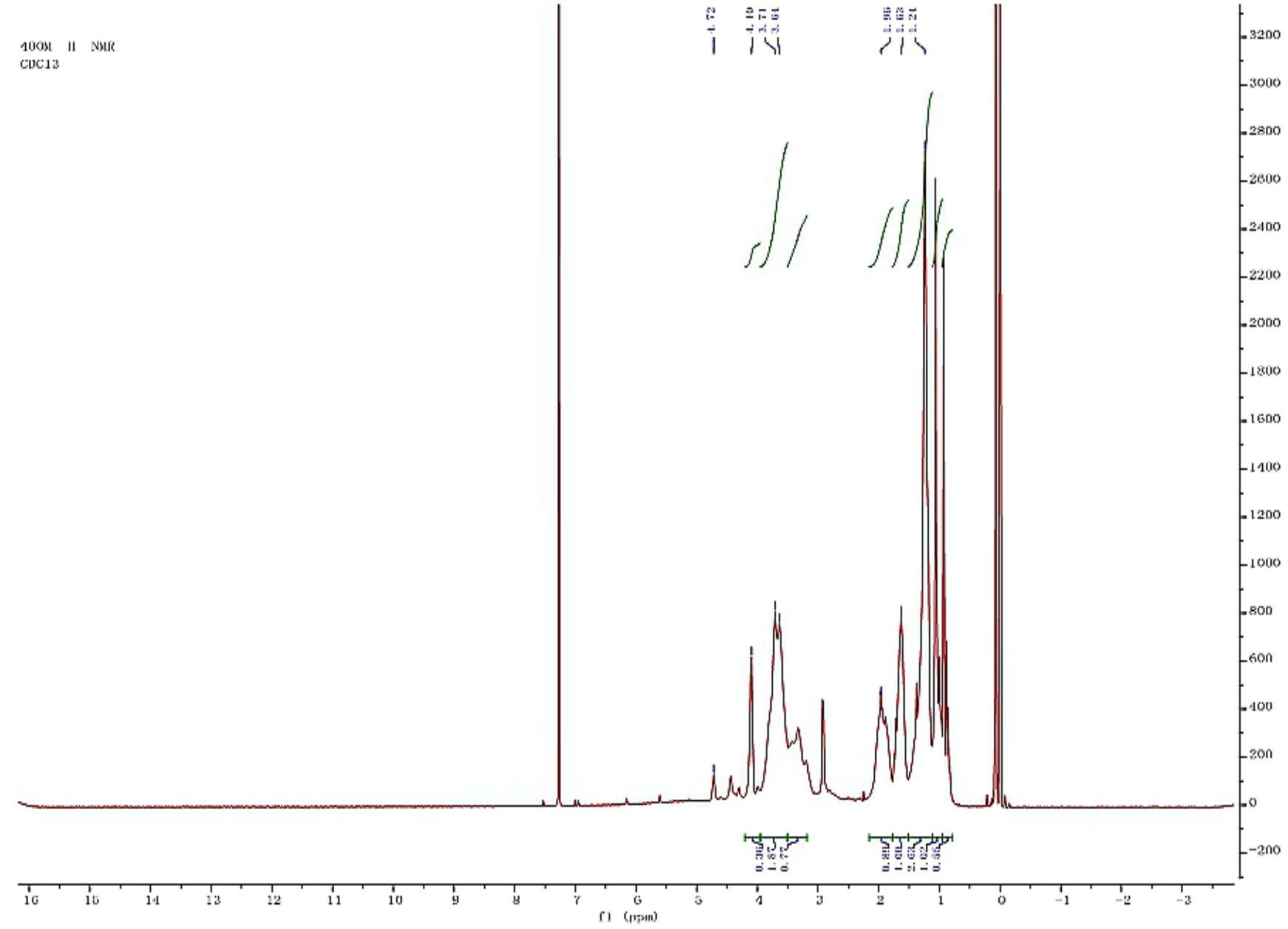

Figure 8. ${ }^{1} \mathrm{HNMR}$ of the synthetic polyurethane(dissolving in $\mathrm{CDCl}_{3}$, tetramethylsilane as an internal standard, $400 \mathrm{MHz}$ of resonance frequency).

As illustrated in Figure 8, the proton peaks of methylene in the residual monomers of epoxycyclohexane are between $\delta 1.0$ and 2.0. In addition, methine in the residual monomers of epoxycyclohexane, and all $\mathrm{H}$ atoms in the residual monomers of epoxychloropropane are between $\delta 3.0$ and 4.0. The chemical shift of the amide proton changes less. It is known that the synthetic product contains carbamate groups, proving that the product is polyurethane.

\subsection{Application of Polyurethane Based on Epoxycyclohexane-Epoxychloropropane Polyether Polyol in Paper}

The effect of polyurethane mass concentration on tensile strength, elongation, folding endurance, and tearing strength of paper were tested $[6,18,19]$. As illustrated in Figure 9a, 
the tensile strength of the paper increased with an increase in the mass concentration of epoxycyclohexane-epoxychloropropane-based polyurethane. When the mass concentration of the polyurethane was $25 \%$, the tensile strength increased from $1105 \mathrm{~N} / \mathrm{m}$ to $3739.4 \mathrm{~N} / \mathrm{m}$, with an increase of $238 \%$. This indicates that polyurethane based on epoxycyclohexaneepoxychloropropane polyether polyol and the paper may form a network, which can strengthen the fibers of the paper; the tensile strength of the coated paper was also effectively improved. Paper elongation is another important indicator of the tensile strength of paper. As shown in Figure 9b, the elongation of the paper in the control group was $0.9 \%$. When the mass concentration of the polyurethane was less than $15 \%$, the elongation increased with an increase in mass concentration. Furthermore, the elongation reached $3.49 \%$ at a mass concentration of $15 \%$, which was $287 \%$ higher than that in the control group. When the mass concentration of the polyurethane was more than $15 \%$, the elongation decreased as the mass concentration rose. In paper fibers, as carbamate bonds replace the hydrogen bonds, the bonding force is enhanced. On the other hand, when there is sustained growth in mass concentration, the paper may become brittle. Consequently, as mass concentration increases, the elongation displays an increase, then a decrease. As Figure $9 \mathrm{c}$ illustrates, the folding endurance of the paper showed a trend of rising and then declining as the mass concentration of polyurethane grew; the trend was the same as elongation. When the mass concentration was $10 \%$, the growth in folding endurance was $8905 \%$, from 20 times to 1801 times. Epoxy cyclohexane has a rigid six-membered ring, so the synthetic epoxycyclohexane-epoxychloropropane-based polyurethane reinforcing solution improves the resistant external forces of paper while coating on the paper. Furthermore, there are more capabilities in the coated paper fibers to hold the original flexibility in the folding process, resulting in a significant increase in both tensile strength and folding endurance. However, when the mass concentration continued to increase, it caused the paper to thicken, leading to significant fracture and embrittlement of the polyurethane coating, and the flexibility of the paper reduced correspondingly. As shown in Figure $9 \mathrm{~d}$, with the increase of the mass concentration, the tearing strength tended to first increase and then decrease. When the mass concentration of the polyurethane was $15 \%$, the tearing strength was $188.2 \mathrm{mN}$, which was $53 \%$ higher than that in the control group. It shows the broken fibers were in interaction due to the synthetic polyurethane [21]. With sustained growth in mass concentration, owing to the increasing steric hindrance of the polyurethane molecules, the bonding force among fibers decreased, causing the peeling of the paper.
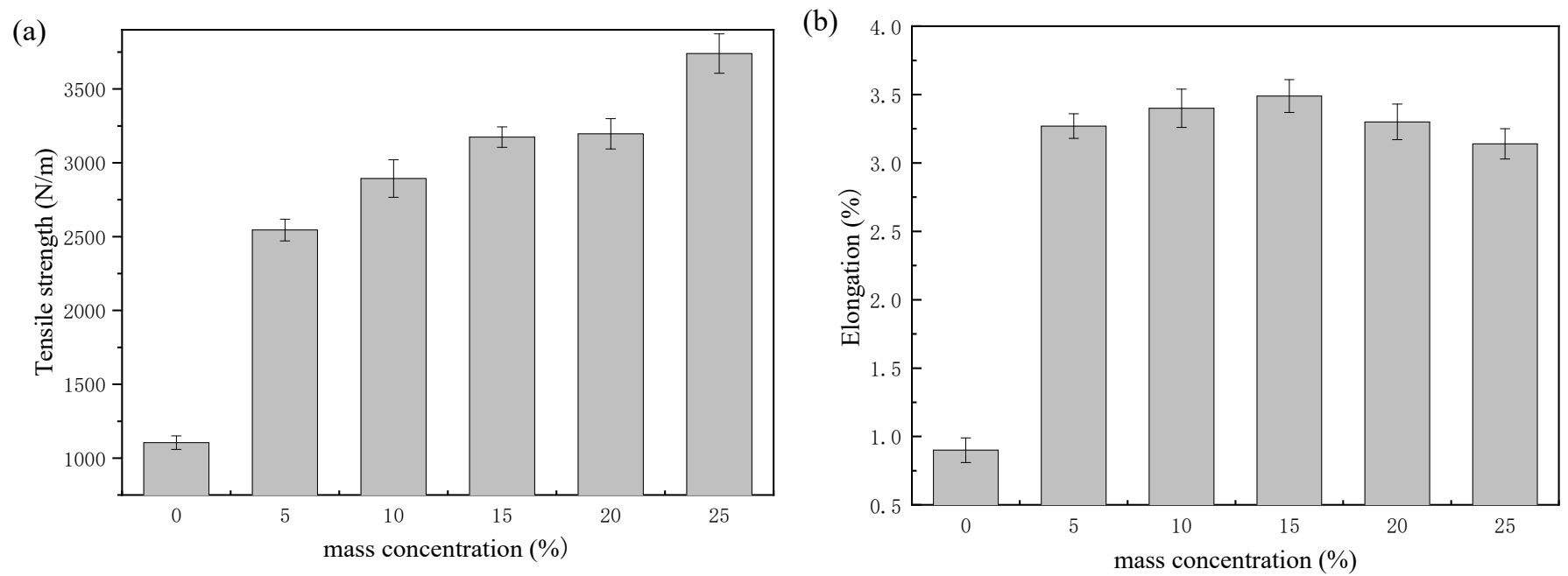

Figure 9. Cont. 
(c)

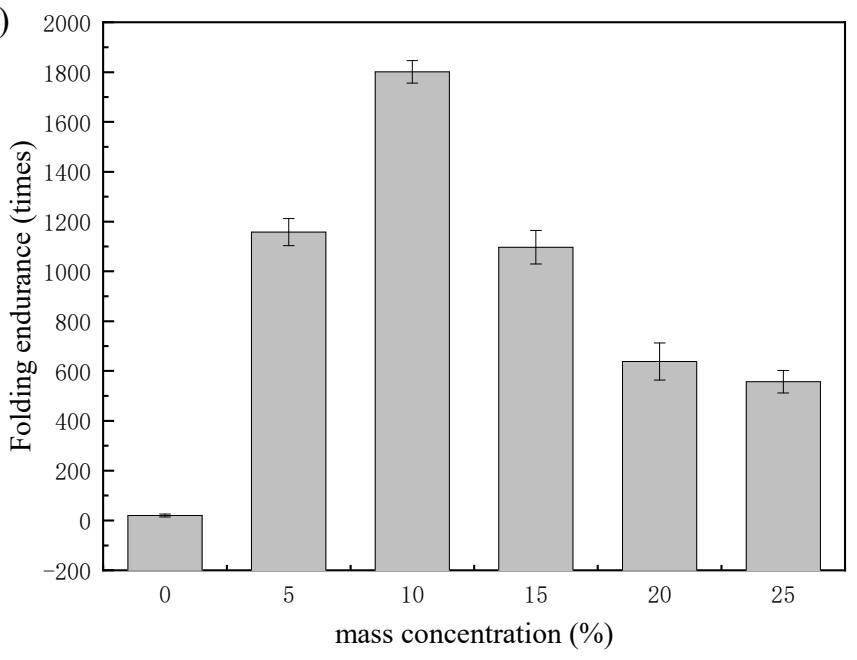

(d)

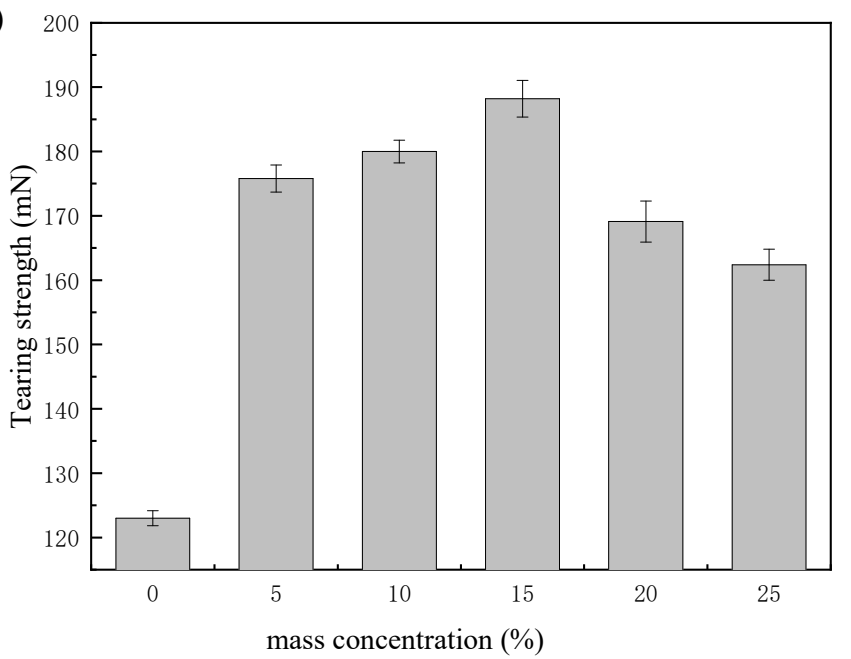

Figure 9. Mechanical properties of the paper treated with different mass concentrations of polyurethane: (a) tensile strength (the paper was cropped to a $24.0 \mathrm{~cm} \times 1.5 \mathrm{~cm}$ size, tested at $20 \mathrm{~mm} / \mathrm{min}$ ); (b) elongation (the paper was cropped to a $24.0 \mathrm{~cm}$ $\times 1.5 \mathrm{~cm}$ size, tested at $20 \mathrm{~mm} / \mathrm{min}$ ); (c) folding endurance (the paper was cropped to a $15.0 \mathrm{~cm} \times 1.5 \mathrm{~cm}$ size, tested at a force of $4.9 \mathrm{~N})$; (d) tearing strength (the paper was cropped to $6.5 \mathrm{~cm} \times 5.0 \mathrm{~cm}$ ).

The effect of mass concentration of the synthetic polyurethane on gloss of the paper is shown in Figure 10.

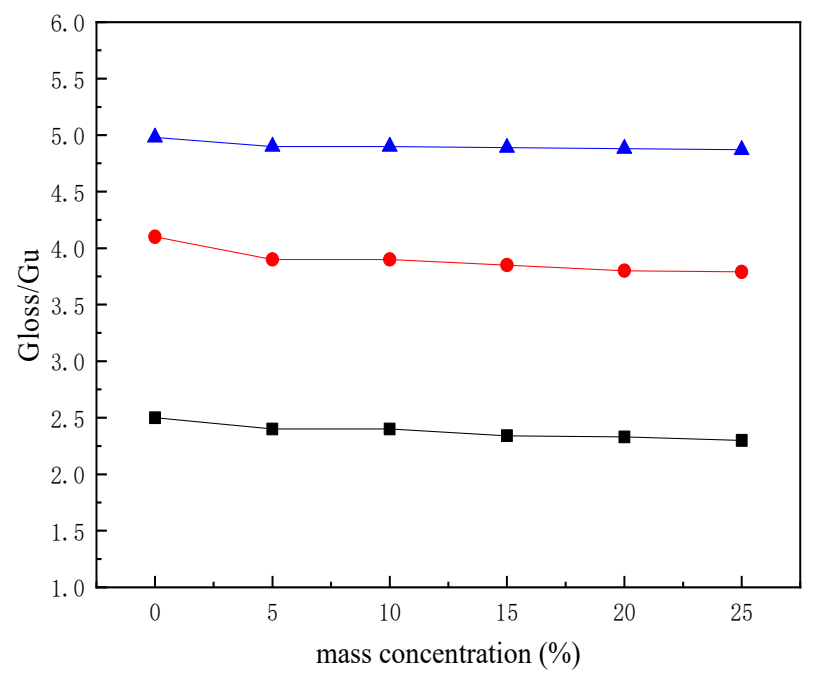

Figure 10. Gloss of the paper treated with different mass concentrations of polyurethane (chosen modes of G20, G60, and G75) $\mathbf{\square}, \mathrm{G} 20 ; \bullet, \mathrm{G} 60 ; \boldsymbol{\Lambda}, \mathrm{G} 75$.

As illustrated in Figure 10, when the mass concentration was less than 15\%, the gloss of the paper gradually decreased with the increasing concentration, but the change is not significant. When the mass concentration was 15\%, the gloss of G20 decreased by $8 \%$ from 2.5 to 2.3, the gloss of G60 decreased by 7\% from 4.1 to 3.8, and the gloss of G70 decreased by $2 \%$ from 4.9 to 4.8 . When the mass concentration was greater than $15 \%$, and increased in concentration, the gloss of the paper began to decline significantly.

The effect of the mass concentration of the synthetic polyurethane on the brightness of the paper is shown in Figure 11. 


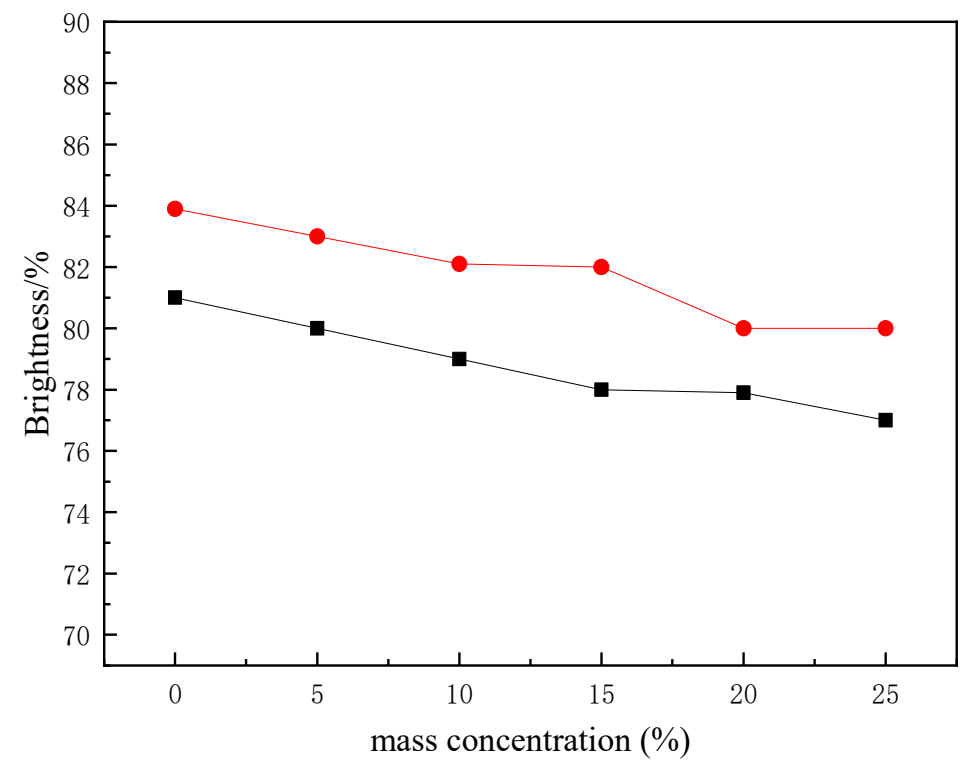

Figure 11. Brightness of the paper treated with different mass concentrations of polyurethane (chosen modes of blue and green light diffuse reflectance spectra, R457 and Ry). $\mathbf{0}, \mathrm{R} 457 ; \bullet \bullet$, Ry.

As shown in Figure 11, with the increase in mass concentration, the brightness of the paper gradually decreased. When the mass concentration was $15 \%$, the R457 whiteness was $78 \%$, with a decrease of $3.7 \%$, and Ry brightness was $82 \%$, with a decrease of $2.3 \%$. Consequently, the synthetic polyurethane has little influence on the brightness of the paper.

Accordingly, after a comprehensive evaluation of the tensile strength, elongation, folding endurance, tearing strength, brightness, and gloss, the optimal mass concentration of polyurethane based on epoxycyclohexane-epoxychloropropane polyether polyol is $10 \%$.

Analysis indicated that the synthetic polyurethane based on epoxycyclohexane- epoxychloropropane polyether polyol was dried to form the coating of the treated paper, filling the gaps in the paper fibers, enhancing the binding force between fibers, actually improving paper performance. By ring-opening polymerization of epoxycyclohexane, the synthetic polyurethane has the solidity of the six-membered ring, improving the paper anti-reciprocating folding ability at a certain tension, benefitting the resistant external forces of paper. In addition, there is more capability in the coated paper fibers to hold the original flexibility in the folding process. In general, the tensile strength, folding endurance, elongation as well as tearing strength have been improved. Coupled with its large steric hindrance, the obtained polyurethane molecular chain is disordered, transparent, not easy to crystallize, and possesses good gloss and brightness. Meanwhile, for the linear structure of epoxychloropropane, the hardness of the copolyether decreases and the fluidity increases [17-19].

An analysis and comparison of applications of previously synthetic polyurethane based on epoxycyclohexane homopolyetheryl and polyurethane based on epoxycyclohexaneepoxychloropropane copolyether in paper reinforcement were studied. This indicated that both the tensile strength of the coated paper improved effectively. As the mass concentration increased, the tensile strength of the paper treated with homopolyetheryl-based polyurethane liquid increased until the mass concentration reached $20 \%$, then the tensile strength declined. With the polyurethane mass concentration growth to $20 \%$, the tensile strength increased from 1105 to $3039 \mathrm{~N} / \mathrm{m}$. However, the tensile strength of the paper increased with the growth of the mass concentration of copolyether-based polyurethane. When the mass concentration of the polyurethane was $25 \%$, the tensile strength increased from $1105 \mathrm{~N} / \mathrm{m}$ to $3739.4 \mathrm{~N} / \mathrm{m}$. In addition, the tensile strength of paper treated by copolyether-based polyurethane was higher than that treated by homopolyetheryl-based polyurethane at each mass concentration. In comparison to elongation, both display similar responses. In contrast to folding endurance, both display rising, and then decrease as 
the mass concentration rises. When the mass concentration of homopolyetheryl-based polyurethane increased to $10 \%$, the folding endurance increased from 20 to 504 times, about 24.2 times higher than that of the blank paper. When the mass concentration of copolyether-based polyurethane was $10 \%$, the folding endurance increased by $8905 \%$ from 20 to 1801 times. In particular, copolyether-based polyurethane gave better results. With the increase of the mass concentration, the tearing strength of both tended to increase first and then decrease. Copolyether-based polyurethane was higher than that treated by homopolyetheryl-based polyurethane at each mass concentration. In conclusion, copolyether-based polyurethane has a better influence on improvement of tensile strength, elongation, folding endurance, and tearing strength of paper [19].

The scanning electron microscope (SEM) images of the paper samples can be seen in Figure 12.
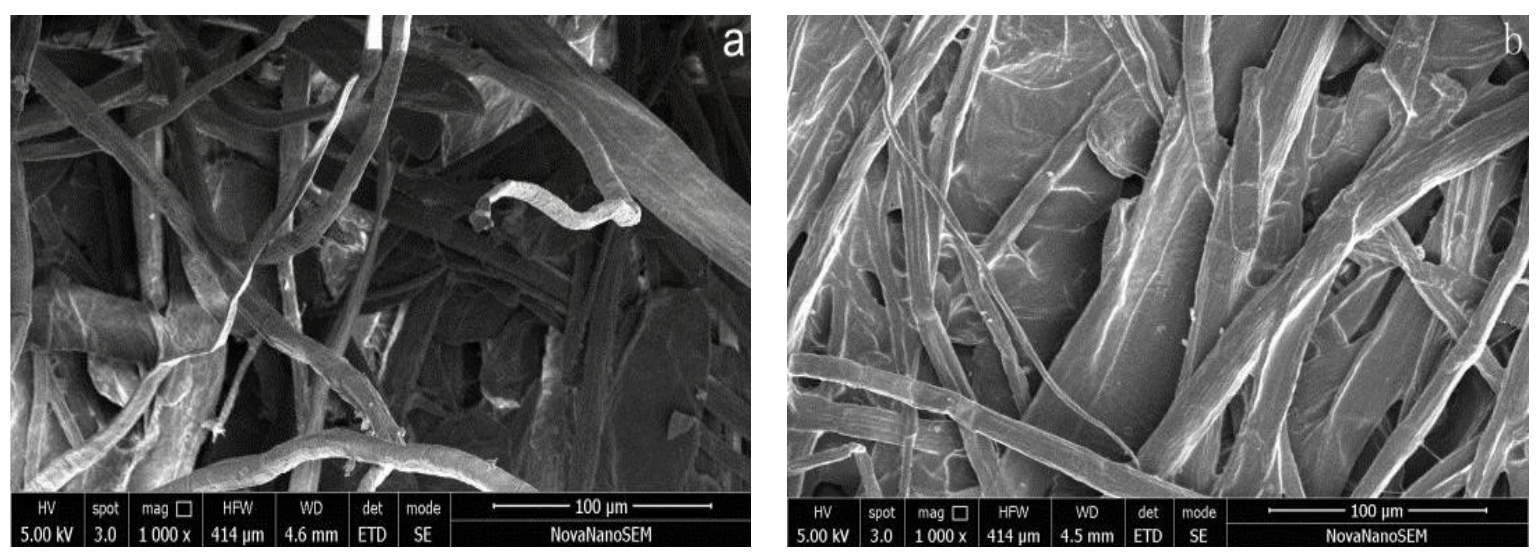

Figure 12. SEM images of Xuan paper treated before (a) and after (b) with polyurethane liquid.

From Figure 12, it can be seen that the fiber distribution of paper in the control group were messy and uneven in thickness, and there were more inter-fiber gaps. The paper fibers in the experimental group that were treated by polyurethane became coarser and evenly dispersed, and the broken fibers of the paper samples were also interacting. Moreover, the inter-fiber gaps were filled by the reinforcement solution, and the paper surface was smoother.

The appearance of the calligraphy work treated before and after with $10 \%$ polyurethane liquid are shown in Figure 13. Evidently, the polyurethane based on epoxycyclohexaneepoxychloropropane polyether polyol was highly transparent, and there was no ink diffusion or changes in the appearance. 

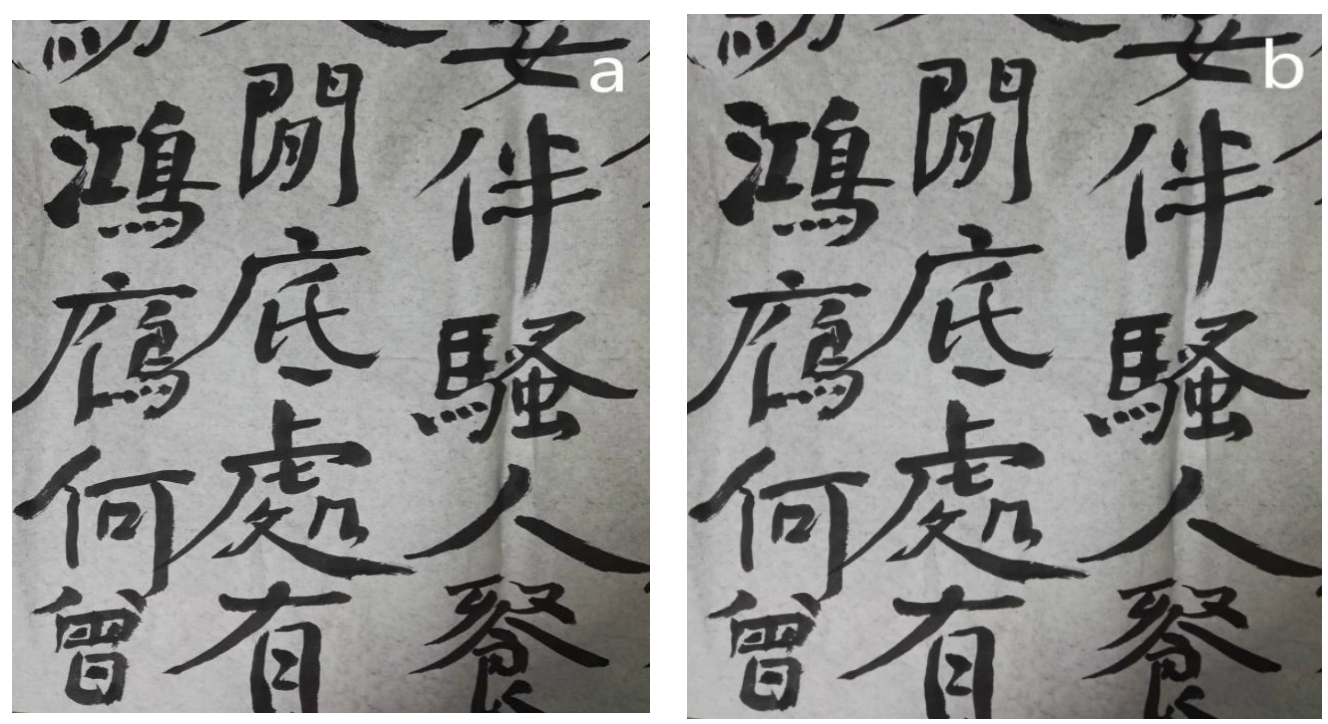

Figure 13. The appearance of the calligraphy work treated before (a) and after (b) with synthetic polyurethane.

\section{Conclusions}

Epoxycyclohexane-epoxychloropropane polyether polyol was obtained by cationic ringopening polymerization, which was characterized by IR spectra and ${ }^{1} \mathrm{HNMR}$ spectroscopy. Polyurethane was then prepared by the synthetic copolyether and HDI trimer. Furthermore, the results of the tests conducted on paper samples coated with $10 \%$ polyurethane liquid indicated that the coated paper presented excellent properties in tensile strength, elongation, folding endurance, and tearing strength. Additionally, the coated paper presented good gloss and brightness. The determination of the appearance of a calligraphy work coating with $10 \%$ polyurethane liquid showed that there was no ink diffusion and no changes in the appearance. Compared to homopolyetheryl-based polyurethane, copolyether-based polyurethane has a better influence on the improvement of mechanical properties of paper. In conclusion, the synthetic polyurethane combines the advantages of epoxycyclohexaneepoxychloropropane polyether polyol and polyurethane, demonstrating excellent properties in paper reinforcement or conservation.

Author Contributions: Conceptualization, H.L. and S.-S.J.; methodology, H.L. and S.-S.J.; validation, H.L., J.L. and S.-S.J.; formal analysis, S.-S.J. and J.L.; investigation, H.L. and S.-S.J.; resources, Y.-P.Q. and Y.-F.S.; data curation, S.-S.J., J.L., Y.-P.Q. and Y.-F.S.; literature retrieval and chart making, J.L.; writing-original draft preparation, S.-S.J., J.L. and H.L., revision of manuscripts, S.-S.J., J.L., Y.-P.Q., Y.-F.S. and H.L.; writing-review and editing, H.L.; supervision, H.L. All authors have read and agreed to the published version of the manuscript.

Funding: This research received no external funding.

Institutional Review Board Statement: Not applicable.

Informed Consent Statement: Not applicable.

Data Availability Statement: Not applicable.

Conflicts of Interest: The authors declare no conflict of interest.

Sample Availability: Samples of the compound epoxycyclohexane-epoxychloropropane polyether polyol are available from the authors.

\section{Abbreviations}

The following abbreviations are used in this manuscript: HDI: hexamethylene diisocyanate, IR: infrared, ${ }^{1} \mathrm{HNMR}$ : proton nuclear magnetic resonance, SEM: scanning electron microscope. 


\section{References}

1. Camargos, C.H.M. Cellulose nanocrystal-based composite for restoration of lacunae on damaged documents and artworks on paper. J. Cult. Herit. 2017, 23, 170-175. [CrossRef]

2. Vohrer, U. Plasma treatment-an increasing technology for paper restoration? Surf. Coat. Technol. 2001, 142, 1069-1073. [CrossRef]

3. Qiao, L. The application of poly(methyl methacrylate-co-butyl acrylate-co-styrene) in reinforcing fragile papers: Experiments and computer simulations. Cellulose 2017, 24, 5157-5171. [CrossRef]

4. El-Feky, O.M. Use of $\mathrm{ZnO}$ nanoparticles for protecting oil paintings on paper support against dirt, fungal attack, and UV aging. J. Cult. Herit. 2014, 15, 165-172. [CrossRef]

5. Afsharpour, M. Preventive protection of paper works by using nanocomposite coating of zinc oxide. J. Cult. Herit. 2017, 25, 142-148. [CrossRef]

6. Jin, S.S. A transparent polyurethane based on nanosilica in reinforcing papers. Nord. Pulp Pap. Res. J. 2020, 36, 82-90. [CrossRef]

7. Melo, D. Stains versus colourants produced by fungi colonising paper cultural heritage: A review. J. Cult. Herit. 2019, 35, 161-182. [CrossRef]

8. $\mathrm{Xu}, \mathrm{J}$. Synthesis of microcrystalline cellulose $/ \mathrm{TiO}_{2} /$ fluorine/styrene-acrylate coatings and the application for simulated paper cultural relic protection. Cellulose 2020, 27, 6549-6562. [CrossRef]

9. Chen, Q. Preparation and application of modified carboxymethyl cellulose Si/polyacrylate protective coating material for paper relics. Chem. Pap. 2016, 70, 946-959. [CrossRef]

10. Totolin, M.I. Positive findings for plasma polymer (meth)acrylate thin films in heritage protective applications. J. Cult. Herit. 2011, 12, 392-398. [CrossRef]

11. Chao-Shi, M.U. Study progress in polyether polyol. Chem. Ind. Dev. 2009, 38, 13-18.

12. Qian, B.Z. Development progress on polyether polyol at home and abroad. FineSpec. Chem. 2010, 18, 5-12.

13. Sung, C.S.P. Properties of segmented polyether poly(urethaneureas) based of 2,4-toluene diisocyanate infrared and mechanical studies. Macromolecules 1980, 13, 117-121. [CrossRef]

14. Adhikari, R. Mixed macrodiol-based siloxane polyurethanes: Effect of the comacrodiol structure on properties and morphology. J. Appl. Polym. 2015, 78, 1071-1082. [CrossRef]

15. Wang, C.B. Morphology and properties of segmented polyether polyurethaneureas. Macromolecules 1983, 16, 775-786. [CrossRef]

16. Miller, J.A. Properties of polyether-polyurethane block copolymers:Effects of hard segment length distribution. Macromolecules 1985, 18, 32-44. [CrossRef]

17. Gui, X. Synthesis of CHO-THF PolyetherTransparent PolyurethaneMaterials; Zhengzhou University: Zhengzhou, China, 2017.

18. Jin, S.S. Study on Conservation Materials of Silicon-Based Polyurethane for Paper Relics; Zhengzhou University: Zhengzhou, China, 2019.

19. Liu, J. Preparation and Application of Polyurethane Coating Material Based on Epoxy Cyclohexane Protective for Paper. Coatings 2021, 11, 431. [CrossRef]

20. Qiao, Y.H. Synthesis of Polyether Polyol and Preparation of Polyurethane Materials Based on Epoxy Cyclohexane and Epichlorohydrin; Zhengzhou University: Zhengzhou, China, 2018.

21. Jin, S.S. Study on the application of oligomers in paper reinforcement protection. J. Chem. 2018, 1, $229-233$.

22. Jin, S.S. The application of organosilicon modifiedpolyurethane in reinforcing traditional paper. Nord. Pulp Pap. Res. J. 2019, 34, 485-494. [CrossRef]

23. Yang, N.N. Study on Synthesis and Properties of Transparent Polyurethane Materials Based on Epoxy Cyclohexane; Zhengzhou University: Zhengzhou, China, 2016.

24. Yan, L. Deteriorated Paper Conservation with Cellulose Solution Based on NaOH/urea Solvent; Zhengzhou University: Zhengzhou, China, 2019.

25. GB/T12914-2008. Paper and Board-Determination of Tensile Properties; Standards Press of China: Beijing, China, 2008.

26. GB/T 457-2008. Paper and Board-Determination of Folding Endurance; Standards Press of China: Beijing, China, 2008.

27. GB/T 455-2002. Paper and Board-Determination of Tearing Resistance; Standards Press of China: Beijing, China, 2002.

28. GB/T 8941-2013. Paper and Board-Measurement of Specular Gloss; Standards Press of China: Beijing, China, 2013.

29. GB/T 7974-2013. Paper, Board and Pulps-Measurement of Diffuse Blue Reflectance Factor-D65 Brightness; Standards Press of China: Beijing, China, 2013.

30. Li, Y. Paper conservation with an aqueous $\mathrm{NaOH} /$ urea cellulose solution. Cellulose 2019, 26, 4589-4599. [CrossRef] 